\title{
Connectivity between juvenile and adult fish populations: do adults remain near their recruitment estuaries?
}

\author{
Bronwyn M. Gillanders* \\ Department of Environmental Biology, University of Adelaide, Adelaide, South Australia 5005, Australia
}

\begin{abstract}
Juvenile snapper Pagrus auratus (Sparidae) were collected from 15 estuaries during the recruitment season of 1998-99 and their otoliths were analysed to determine concentrations of chemical elements. Differences in elemental composition of juveniles were found among estuaries or groups of estuaries suggesting that the nursery or recruitment estuary of adult fish could be determined by analysing the juvenile region of adult otoliths. Adult fish from the commercial fishery in the vicinity of Sydney, New South Wales, Australia were then collected, their ages estimated and fish with birth years during 1998-99 selected for microchemical analysis to determine their recruitment estuary. Maximum likelihood analyses were used to determine the proportion of juvenile fish and adult fish from different regions (Wallis Lake, Sydney estuaries, Eden, and other estuaries). For juvenile fish, the actual composition ranged from 7 to $53 \%$ depending on the estuary or group of estuaries and the estimate of proportion of juveniles from the different estuaries ranged from 7.24 to $48.21 \%$ suggesting an error rate of $<1$ to $4.79 \%$. Most ( $89 \%$ ) adult fish caught as part of the snapper fishery in the Sydney region originated from local estuaries, although about $9 \%$ of fish had Eden as their recruitment estuary and $2 \%$ had come from the remaining estuaries excluding Wallis Lake, which contributed no fish. These results suggest that adults on reefs outside estuaries in the Sydney region have come from the estuaries closest to them with little transfer from other estuaries. For other regions, 2 scenarios are possible, namely, adults originated from estuaries close by with little transfer from other estuaries, or alternatively estuaries in the vicinity of Sydney supply the majority of adult fish along the coast. The latter situation is considered unlikely. Results show a link between juvenile and adult populations and suggest that populations of snapper may be self-sustaining or relatively closed.
\end{abstract}

KEY WORDS: Estuary · Coastal population $\cdot$ Fish $\cdot$ Otolith chemistry $\cdot$ Trace elements

\section{INTRODUCTION}

Understanding connectivity among populations of marine organisms is vital for studying population dynamics, managing fish stocks, designing marine protected areas and determining whether populations are open or closed. However, determining spatial connectivity of different life history stages and timing of movement between juvenile and adult populations

*E-mail: bronwyn.gillanders@adelaide.edu.au remains poorly understood. For example, although many fish species recruit to estuarine nursery habitats before moving to coastal habitats, the proportion of individuals in harvested populations that have spent time in different estuaries as juveniles is unknown. In addition, it is not known whether all estuaries contribute equally to maintaining local stocks or whether one or a few estuaries are important source areas of juveniles for many stocks of adults. As habitats within estuaries continue to be degraded, it becomes more important to determine connectivity between spatially segregated juvenile and adult populations. 
Quantifying rates of exchange of marine organisms using conventional tagging techniques is difficult because of the small size of larvae and juveniles, high rates of mortality at early life history stages and the large numbers that need to be tagged in order to recover a sufficient sample size. Alternative methods for determining the origins and movement of organisms are needed. Recently, the interpretation of biological markers such as isotopic and elemental composition has been developed to determine connectivity between populations (e.g. Gillanders \& Kingsford 1996, DiBacco \& Levin 2000, Thorrold et al. 2001).

Many calcified structures have been used as natural tags, e.g. corals, bivalves and seal teeth. The major structure of fish used as a natural tag has been the ear bones or otoliths. The acellular and metabolically inert nature of otoliths means that many of the elements that are used as a natural tag and accreted onto the growing surface of the otolith are permanently retained (Campana 1999). The otolith continues to grow through time recording the entire lifetime of the fish. Differences in microchemistry between otolith layers can be resolved to within days or years of their deposition. The calcium carbonate and trace elements that make up $90 \%$ of the otolith are derived primarily from the water (but see Kennedy et al. 2000), although in practice there are likely to be physiological filters that preclude simple linear relationships between water and otolith composition (Campana 1999). Analyses of either whole otoliths or small areas of an otolith have been used to distinguish stocks or sub-populations within marine species (Edmonds et al. 1989, 1991, 1992, Campana et al. 1994, Campana \& Gagne 1995, Proctor et al. 1995), to reconstruct the history of water temperatures experienced by a fish throughout its life (Patterson et al. 1993) and to detect anadromy (Kalish 1990, Secor 1992, Coutant \& Chen 1993).

This study investigates potential movement between estuarine and open coastal habitats for snapper Pagrus auratus (Sparidae) using an application of otolith chemistry. In New South Wales, Australia, snapper recruit to bare substrata of estuarine habitats where they remain for 12 to $18 \mathrm{mo}$, after which time they move to coastal reefs and other habitats over the continental shelf (Bell \& Worthington 1993). Commercial fishers take adult snapper by inshore trap and line fishery, where the average age of fish taken is $3 \mathrm{yr}$. The general objective of this study was to determine the recruitment estuary, i.e. the estuary to which these adult fish had recruited as juveniles. The specific aims were to: (1) determine the elemental fingerprints of juvenile snapper collected from different estuaries along the coast of New South Wales, Australia, and (2) determine the recruitment estuary of snapper of the 2 yr age class by analysing the region of the otolith that was laid down when the fish was a juvenile. Because the chemical signal laid down in the otoliths varies both amongst estuaries and amongst years (e.g. Gillanders 2002) there was potential to confound temporal differences with spatial differences. Consequently, it was necessary to determine the recruitment estuary of $2^{+}$adult fish based on the chemical signal of otoliths from juveniles collected 2 yr earlier.

\section{MATERIALS AND METHODS}

Sample collection. Juvenile snapper Pagrus auratus (Sparidae) were collected between November 1998 and February 1999 to determine variation in elemental fingerprints among estuaries; 10 fish were collected from each of 2 sites (separated by hundreds of metres to kilometres) in each of 15 estuaries (separated by tens to hundreds of kilometres) spanning $600 \mathrm{~km}$ along the coast of New South Wales, Australia (Fig. 1). All fish were collected by hand line and were stored on ice in the field before being dissected on return to the laboratory. For each fish, the standard length (SL) was measured (range: 44 to $83 \mathrm{~mm}$; mean $\pm \mathrm{SE}$ : $67 \pm 0.5 \mathrm{~mm}$ ), and the sagittal otoliths removed, cleaned of adhering tissue in Milli-Q water, air-dried and placed in Eppendorf microcentrifuge tubes.

Adult snapper from the Sydney region were sampled at the Sydney Fish Markets, as part of the NSW Fisheries snapper monitoring program. The sagittal otoliths were removed, rinsed and stored dry in paper envelopes for latter analysis. One sagittal otolith was prepared for ageing by sectioning through the focus with a low speed saw. The resulting section was polished on an abrasive sheet with water and mounted on a standard microscope slide. Thin sections were viewed with reflected light at a magnification of $20 \times$ on a compound microscope and age estimated from the count of opaque increments. In addition, the edge type was noted as opaque or translucent. Using the estimated age and whether the edge was opaque, the birth summer of the fish was calculated. Fish with a birth summer of 1998-1999 ( $\mathrm{n}=34$ ) were used for subsequent microchemical analysis.

Sample preparation. Otoliths from recruits and adults were sectioned through the primordium with a low speed saw. The resulting section was polished on an abrasive sheet with Milli-Q water and sonicated for $5 \mathrm{~min}$ before being rinsed several times in Milli-Q water. It was then placed in a plastic laminar flow cabinet to dry overnight. Sections were then mounted on microscope slides and individually placed in plastic bags ready for analysis using laser ablation inductively coupled plasma-mass spectrometry (LA ICP-MS). 
Analytical methods. The LA ICP-MS system at the Department of Earth Sciences, Monash University consists of a Merchantek LUV266 petrographic ultraviolet laser (Nd:YAG) microprobe connected to a Finnigan MAT ELEMENT high resolution ICP-MS. The ICP-MS instrument was operated in low resolution $(\mathrm{m} / \Delta \mathrm{m}=$ 300 mode). The sample to be analysed was placed in the ablation chamber and viewed remotely on a computer screen where the area for ablation could be selected. The laser was focused on the sample surface and was fired through the microscope objective lens. The ablated material was entrained in argon and helium gas for analysis of ${ }^{25} \mathrm{Mg},{ }^{44} \mathrm{Ca},{ }^{55} \mathrm{Mn},{ }^{88} \mathrm{Sr}$ and ${ }^{138} \mathrm{Ba}$ isotopes by ICP-MS. Calcium was used as an internal standard to correct for variations in ablation yield. Calcium concentration was assumed from the stoichiometry of calcium carbonate as $400000 \mathrm{\mu g} \mathrm{g}^{-1}$ and the concentration of other elements were estimated against the Ca concentration (Ludden et al. 1995).

At the beginning and end of each day of analysis background counts were collected for $60 \mathrm{~s}$ and the variation among these counts was used to calculate limits of detection. Before each sample, 20 to $30 \mathrm{~s}$ of blank counts were determined, the average of which was used for subtraction from that sample. After about 20 to $30 \mathrm{~s}$ of blank counts, the sample was ablated using a spot size of $100 \mu \mathrm{m}$. Only 1 crater was ablated for each sample because preliminary analyses showed that there was greater variation between otoliths of different fish than within otoliths of the same fish. To correct for instrument drift NIST 612 standards were analysed every 10 to 12 samples and a linear interpolation between the 2 consecutive sets of standards made. A pressed powder snapper standard was also analysed prior to any otolith samples and at the end of each day of analysis.

Detection limits, which were calculated from the concentration of analyte yielding a signal equivalent to $3 \times$ the standard deviation of the blank signal, for each of the elements were: $0.861 \mu \mathrm{g} \mathrm{g}^{-1}(\mathrm{Mg}), 0.066 \mu \mathrm{g} \mathrm{g}^{-1}(\mathrm{Mn})$,

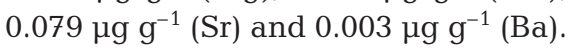
All sample concentrations were above the limits of detection. Mean estimates of precision $(\% \mathrm{RSD}$, relative standard deviation) based on replicate measurements of (1) our pressed powder snapper standard were: $13.8 \%(\mathrm{Mg})$, $24.4 \%(\mathrm{Mn}), 3.4 \%(\mathrm{Sr})$, and $7.0 \%(\mathrm{Ba})$, and (2) NIST 612 standard treated as an unknown were: $9.7 \%(\mathrm{Mg})$, $4.3 \%(\mathrm{Mn})$, and $2.3 \%$ ( $\mathrm{Sr}$ and $\mathrm{Ba}$ ). Mean recoveries based on a NIST 612 standard being treated as an unknown were: $99 \%(\mathrm{Mg})$, and $101 \%(\mathrm{Mn}, \mathrm{Sr}$ and $\mathrm{Ba})$.

All data reduction was carried out off-line using spreadsheet programs and involved determining the average of the background counts and subtracting this from the average of the sample counts. Data (counts $\mathrm{s}^{-1}$ ) were then converted to concentrations using the equation of Ludden et al. (1995):

$$
\left[C_{X}\right]_{s a m p}=\frac{\left[I_{(m, X)} / I_{(m, I s)}\right]_{s a m p} \times\left(C_{I s}\right)_{s a m p} \times\left(C_{m, X}\right)_{s t d}}{\left[I_{(m, x)} / I_{(m, I s)}\right]_{s t d} \times\left(C_{I s}\right)_{s t d}}
$$

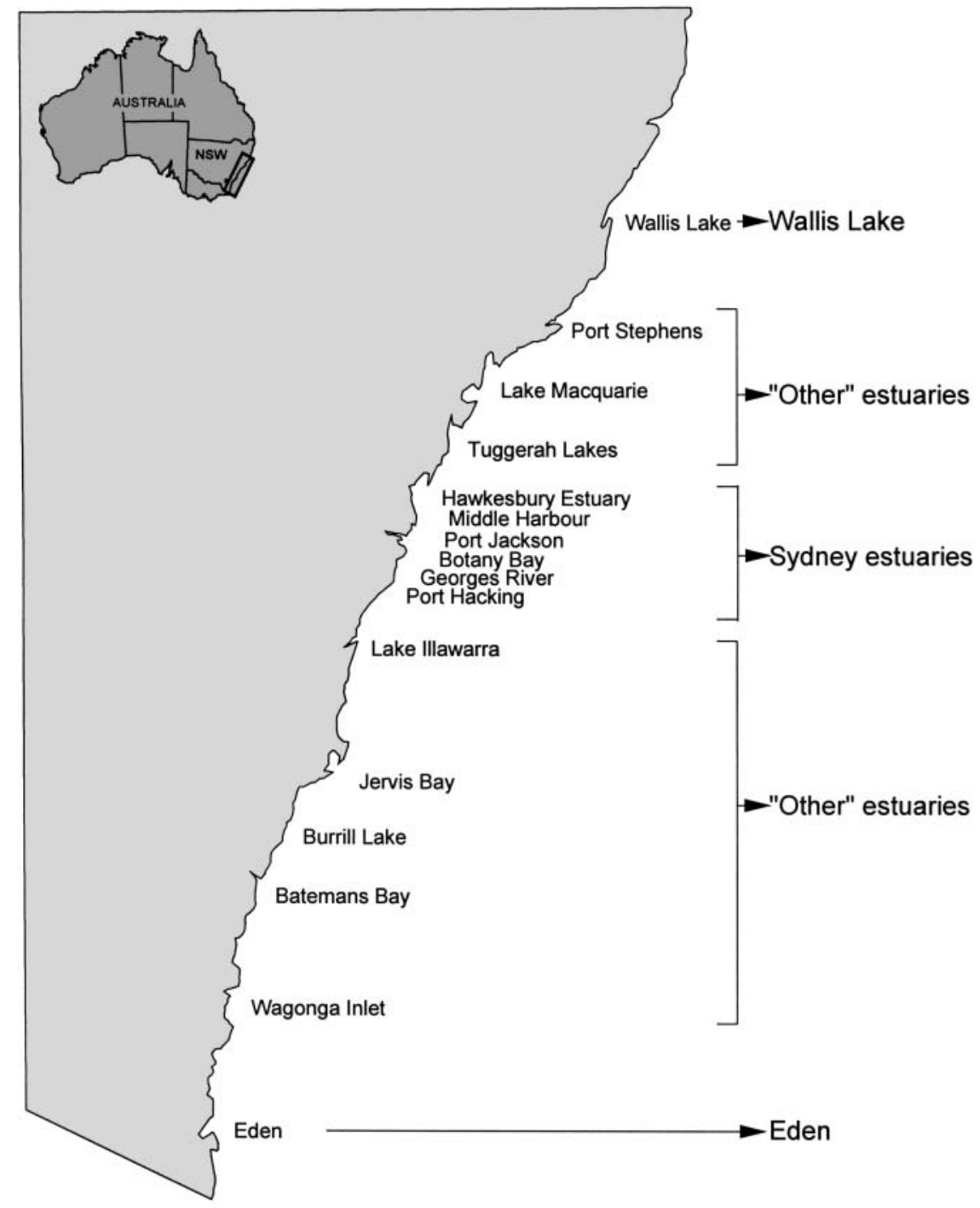

Fig. 1. New South Wales coast, showing estuaries in which snapper were collected, and the groupings of estuaries for the maximum likelihood analyses 
where (Is) is the internal standard (in this case ${ }^{44} \mathrm{Ca}$ ), $I_{(m, x)}$ is the intensity at mass $x$ of the element being sought, and $C_{(m, x)}$ is the concentration of the element of mass $x$ in the standard.

Statistical methods. To determine whether there were significant differences among estuaries for individual elements and multielement fingerprints, analysis of variance (ANOVA) and multivariate analysis of variance (MANOVA) were used. Both types of analy- ses involved 2-factor designs and both terms (estuary and site) were considered random factors. Site was nested within the estuary term. All analyses were performed on $\ln (x+1)$ transformed data. The MANOVA used a non-parametric technique incorporating permutation tests (Anderson 2001). The method of permutation involved permuting the raw data; further details on methods of permutation can be found elsewhere (Manly 1997).

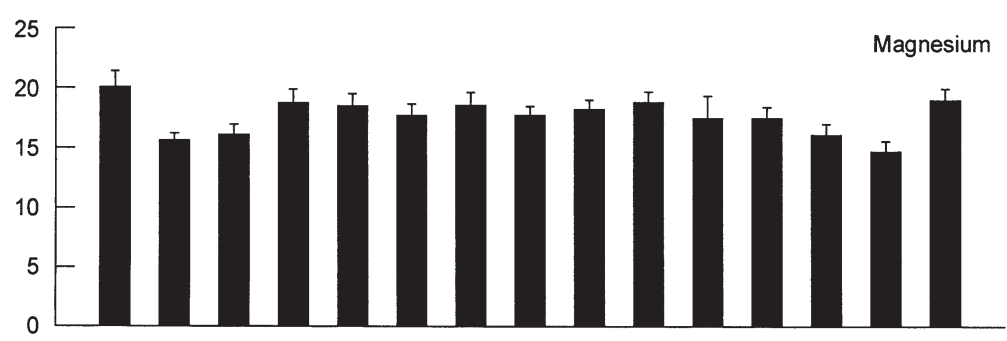

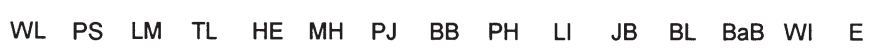
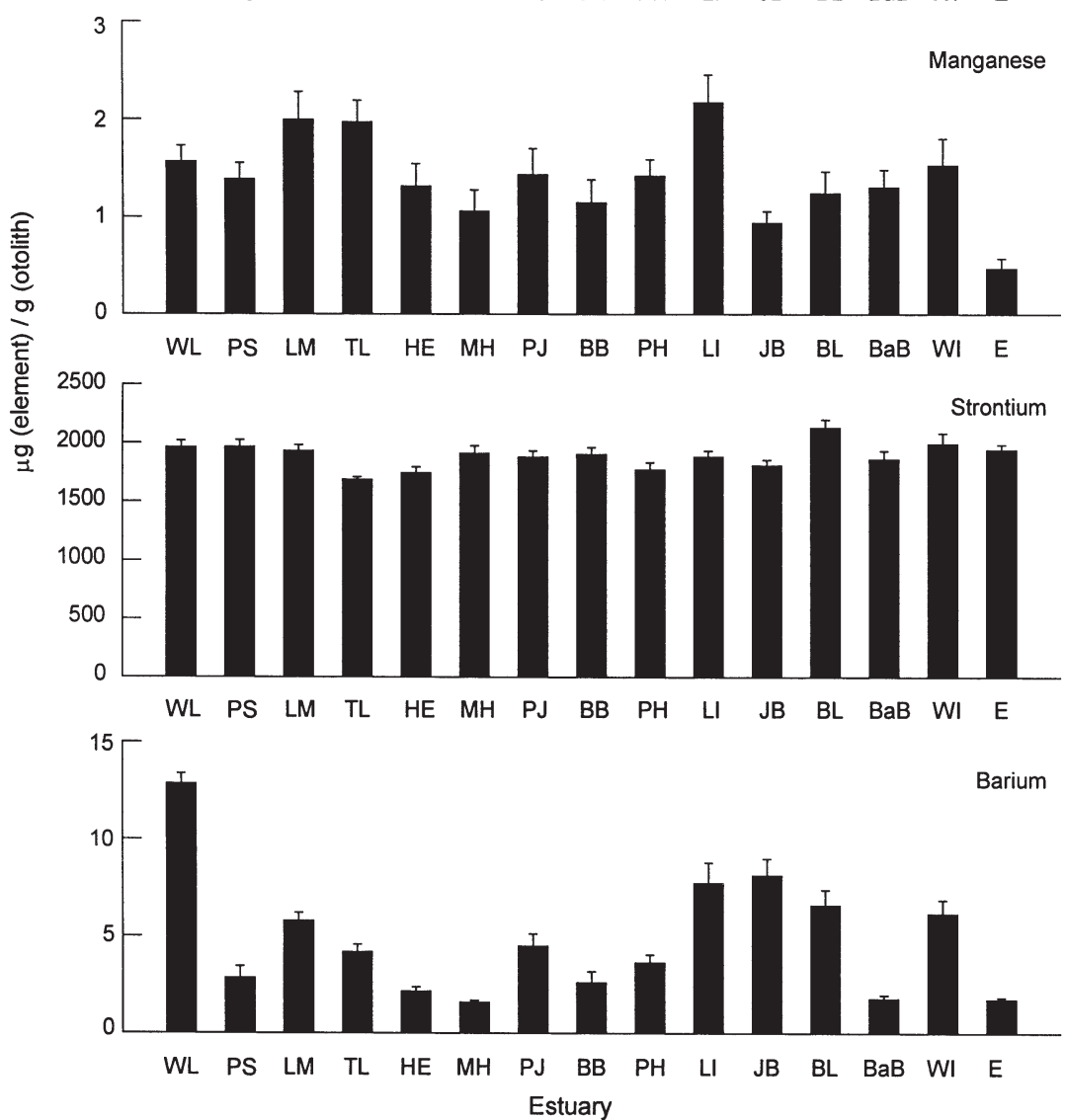

Fig. 2. Pagrus auratus. Mean concentration $( \pm \mathrm{SE})$ of $\mathrm{Mg}, \mathrm{Mn}, \mathrm{Sr}$ and $\mathrm{Ba}$ in otoliths of juveniles collected from 15 estuaries along the coast of New South Wales, Australia. The data were pooled for 2 sites within each estuary ( $\mathrm{n}=20$ fish per estuary). The estuaries were Wallis Lake (WL), Port Stephens (PS), Lake Macquarie (LM), Tuggerah Lakes (TL), Hawkesbury Estuary (HE), Middle Harbour (MH), Port Jackson (PJ), Botany Bay (BB), Port Hacking (PH), Lake Illawarra (LI), Jervis Bay (JB), Burrill Lake (BL), Batemans Bay (BaB), Wagonga Inlet (WI) and Eden (E)
A maximum likelihood based analysis was used to determine (1) the ability of elemental fingerprints to record correctly the proportion of recruits from different estuaries, and (2) the proportion of adult fish originating from the different estuaries/groups of estuaries. The maximum likelihood estimator was chosen because it performs better than classification-based estimators and provides maximum discriminatory power in mixed stock situations (Millar 1987, 1990a). Results were obtained from a multipurpose simulation-bootstrap-analysis program (Millar 1990b). The program was initially run in simulation mode using the juvenile elemental data. The 15 estuaries were too many to discriminate amongst, based on only 4 discriminatory variables ( $\mathrm{Mg}$, $\mathrm{Mn}, \mathrm{Sr}, \mathrm{Ba})$, and therefore the estuaries were grouped into 4 regions (Wallis Lake, Sydney region, Eden and 'Others'). Estuaries were grouped based on similarities in elemental signatures of juvenile otoliths. The absolute error was estimated as the difference between the actual or known contribution of juveniles and the estimated mean contribution. One hundred simulations were made using the juvenile data to estimate the variability of the estimator. The procedure used for estimating variability was bootstrapping or resampling the data with replacement (see Millar 1990a,b). In simulation mode, 100 simulations were made and the data used to provide an estimate of the variability of the estimator. The second analysis then involved using the juvenile elemental fingerprints from 1998/1999 as the baseline data for which estuarine affinity was known, and running the program in bootstrap mode to estimate the proportion of adults from each estuary or group of 
estuaries. Thus, the adult elemental fingerprints were used as the mixed fishery data. Again, 100 simulations provided an estimate of variability associated with the proportion of adult fish estimated to be from each estuary or group of estuaries.

\section{RESULTS}

\section{Juvenile fish}

Mn and Ba both showed significant variation among estuaries (Fig. 2, Table 1). Otoliths of fish from Eden had significantly lower amounts of Mn than those from the other estuaries. Greater amounts of Mn were found in otoliths of fish from Lake Macquarie, Tuggerah Lakes and Lake Illawarra. For Ba, otoliths of fish from Wallis Lake had significantly greater levels than fish from elsewhere. Several estuaries, namely Hawkesbury Estuary, Middle Harbour, Batemans Bay and Eden produced low readings of Ba. No significant differences among estuaries were found for $\mathrm{Mg}$ and $\mathrm{Sr}$. Significant differences were also found between sites within an estuary for Sr and Ba (Table 1).

Significant differences were found in multielement fingerprints among estuaries and between sites within an estuary (Fig. 3, Table 1). The 95\% confidence ellipses around the mean value for each estuary suggested that some estuaries such as Wallis Lake and

Table 1. Pagrus auratus. ANOVA among estuaries and between sites for individual elements ( $\mathrm{Mg}, \mathrm{Mn}, \mathrm{Sr}$ and $\mathrm{Ba}$ ) and the multivariate fingerprint for otoliths of juveniles

\begin{tabular}{|lrrrc|}
\hline Source & df & MS & $F$ & P \\
\hline Mg & & & & \\
Estuary & 14 & 0.1316 & 1.80 & 0.1349 \\
Site (estuary) & 15 & 0.0730 & 1.55 & 0.0885 \\
Residual & 270 & 0.0472 & & \\
Mn & & & & \\
Estuary & 14 & 0.6979 & 3.79 & 0.0075 \\
Site (estuary) & 15 & 0.1842 & 1.32 & 0.1876 \\
Residual & 270 & 0.1392 & & \\
Sr & & & & \\
Estuary & 14 & 0.0645 & 1.53 & 0.2125 \\
Site (estuary) & 15 & 0.0422 & 2.45 & 0.0022 \\
Residual & 270 & 0.0172 & & \\
Ba & & & & \\
Estuary & 14 & 5.0265 & 11.44 & 0.0000 \\
Site (estuary) & 15 & 0.4394 & 3.26 & 0.0001 \\
Residual & 270 & 0.1346 & & \\
Mg, Mn, Sr \& Ba & & & & \\
Estuary & 14 & 5.9123 & 8.0161 & 0.0002 \\
Site (estuary) & 15 & 0.7375 & 2.1870 & 0.0030 \\
Residual & 270 & 0.3372 & & \\
\hline
\end{tabular}

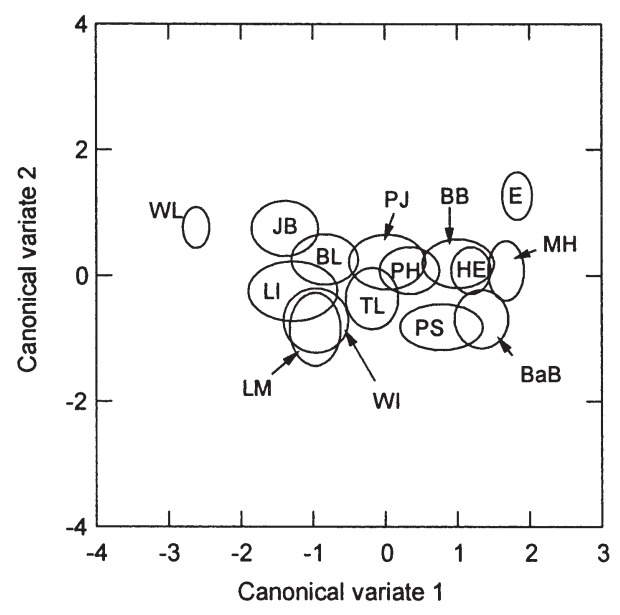

Fig. 3. Pagrus auratus. Plot summarising variation in elemental fingerprints of otoliths of juveniles collected from different estuaries along the coast of New South Wales, Australia. Ellipses represent bootstrapped 95\% confidence intervals ( $n=1000$ ) around the means of each estuary for each canonical variate. See caption to Fig. 2 for estuary abbreviations

Eden had quite different elemental fingerprints compared with the rest (Fig. 3). There were, however, a number of estuaries that overlapped with others particularly those in the vicinity of Sydney: Hawkesbury Estuary, Port Jackson, Middle Harbour, Botany Bay and Port Hacking. This suggests that these estuaries can be grouped to determine recruitment estuaries of adult snapper.

Maximum likelihood based estimation was used to determine the ability of elemental fingerprints to record correctly the proportion of recruits from different estuaries. The actual contribution ranged from 7 to $53 \%$ depending on the estuary or group of estuaries (Table 2a). The estimate of percentage of recruits from the different estuaries ranged from 7.24 to $48.21 \%$

Table 2. Pagrus auratus. Results of maximum likelihood analyses for (a) juveniles, and (b) unknown adults

\begin{tabular}{|lccc|}
\hline Estuary & $\begin{array}{c}\text { Actual } \\
\text { contribution }\end{array}$ & $\begin{array}{c}\text { Estimated } \\
\text { contribution }\end{array}$ & SD \\
\hline (a) Juveniles & & & \\
Wallis Lake & 0.07 & 0.1000 & 0.0864 \\
Other & 0.53 & 0.4821 & 0.1930 \\
Sydney & 0.33 & 0.3455 & 0.1939 \\
Eden & 0.07 & 0.0724 & 0.0764 \\
(b) Adults & & & \\
Wallis Lake & & 0.0000 & 0.0000 \\
Other & & 0.0199 & 0.0352 \\
Sydney & & 0.8944 & 0.1285 \\
Eden & & 0.0857 & 0.1243 \\
\hline
\end{tabular}


suggesting an error rate of $<1$ to $4.79 \%$, although this error rate has not taken into account the variability in the simulation runs (Table 2a). The greatest error was associated with the grouping of estuaries labelled Other, whilst the estimates of error for Wallis Lake, Eden and the Sydney estuaries were less than $3 \%$. The variability in the estimates of proportion of juvenile snapper from each estuary ranged from 7.64 to $19.39 \%$ being greatest for Sydney and 'Other' estuaries.

\section{Adult fish}

Maximum likelihood based estimation was used to determine the proportion of adult snapper that originated from the different estuaries. Most snapper (89\%) caught in the Sydney region originated from local estuaries, namely Hawkesbury Estuary, Middle Harbour, Port Jackson, Botany Bay or Port Hacking (Table 2b). About $9 \%$ of snapper had Eden as their recruitment estuary and $2 \%$ had come from the remaining estuaries excluding Wallis Lake, which contributed no snapper. These estimates of the proportion of adult snapper originating from the various estuaries do not take account of potential variability in the maximum likelihood based estimator. Results from 100 simulations of the data showed that the variability ranged from $0 \%$ (Wallis Lake) to $12.85 \%$ (Sydney estuaries). After taking into account the variability for the estimated proportions, between 77 and $100 \%$ of adults on reefs outside estuaries had come from the estuaries closest to them.

\section{DISCUSSION}

The concentration of some elements in the otoliths of snapper recruits varied among estuaries. For example, Ba was significantly greater in otoliths of fish collected from Wallis Lake than the other estuaries, whereas Mn occurred in greater concentrations in otoliths of snapper from Lake Illawarra, Lake Macquarie and Tuggerah Lakes. This meant that elemental fingerprints that were representative of a number of estuaries could be used to distinguish amongst snapper recruits. Although the causal factors responsible for these spatial differences are not known, these differences have enabled the use of elements to reconstruct past life history.

Use of otolith elemental fingerprints as natural tags must meet 3 assumptions, namely: (1) there are significant differences in the elemental fingerprints of the groups of interest, (2) all possible groups contributing to the group mixture have been characterised, and (3) the fingerprint remains stable over the interval between characterisation and mixing (Campana 1999, Campana et al. 2000). The elemental fingerprints of juvenile snapper showed significant differences among estuarine groups. While many studies have found group-specific variation in elemental composition (Edmonds et al. 1989, 1991, 1992, Campana \& Gagne 1995, Campana et al. 1995, Thorrold et al. 1997), including among estuaries (Thorrold et al. 1998, Gillanders \& Kingsford 2000) and between estuaries and coastal reefs (Gillanders \& Kingsford 1996), this is not always the case (Kalish et al. 1996, Gillanders et al. 2001) and needs to be assessed empirically.

To satisfy the second assumption, juvenile fish were collected from as many estuaries as possible in order to characterise all potential groups. If some estuaries remain uncharacterised then it is possible that adult fish are characterised to an incorrect recruitment estuary. While there are over 80 estuaries along the coast of New South Wales (Bucher \& Saenger 1991), many are open for relatively short periods of time (or not at all) and therefore may not be available as recruitment habitats for snapper. Once snapper have recruited, the estuary must be open for subsequent movement to the adult population. In addition, many estuaries along the coast of New South Wales are relatively small (area of water $<10 \mathrm{~km}^{2}$, West et al. 1985) and may not contribute greatly to adult populations. Of the estuaries between Wallis Lake and the NSW/Victoria border that have a greater surface area than $10 \mathrm{~km}^{2}$, snapper were collected and elemental fingerprints determined for $70 \%$ of them. In addition, some smaller estuaries were also sampled. In past studies, it is not clear whether all possible groups have been characterised, however, it is vital that as many groups as possible are characterised if mistakes about origins are to be avoided.

Elemental fingerprints of some species vary among different recruitment seasons (Gillanders \& Kingsford 2000, Gillanders 2002). Campana et al. (2000) found that elemental concentrations varied little over $2 \mathrm{yr}$ intervals, but more substantive differences were noted for some elements (e.g. Li, Mg, Ba) and some locations over 4 to 13 yr intervals. However, a number of other studies have found significant variation in otolith chemistry over 2 to 3 yr intervals (Milton et al. 1997, Dove \& Kingsford 1998, Patterson et al. 1999, Gillanders \& Kingsford 2000, Rooker et al. 2001). Variation over short time periods has significant implications for solution-based analyses of whole otoliths, as this implies that the elemental fingerprint may change from one time of sampling to the next. For laser-based analyses, variation in elemental fingerprints over time suggests that similar regions of juvenile and adult otoliths need to be sampled, as was done in the current study (see below). In addition, variation in elemental 
fingerprints among years does not preclude determining recruitment estuaries of adults, but it does suggest that adults need to be tracked back to recruitment estuaries using elemental fingerprints developed on recruits from the year class in which the adults of interest were in the estuary. Thus in the current study, since the elemental fingerprints were determined for juveniles that originated in 1998/99, it was necessary that the adults that were subsequently sampled originated in that year.

A laser-based approach was used to sample the otoliths of juveniles and adults. The area of each otolith sampled (20 to $30 \mathrm{~d}$ period) was that which would have formed during the period in the estuarine habitat. A similar approach was used by Thorrold et al. (2001) to determine homing of spawning weakfish Cynoscion regalis to natal estuaries. Gillanders \& Kingsford (1996) used a solution-based approach to analyse whole juvenile otoliths from 2 types of habitat (estuarine seagrass and algal reef) and cores of adult blue groper Achoerodus viridis otoliths and thereby determine recruitment habitats of adult fish collected on the reef. Analyses of whole otoliths of cod Gadus morhua collected from known spawning grounds were also used as the baseline data from which to characterise mixed over-wintering schools (Campana et al. 2000).

More than $97 \%$ of commercial landings of snapper in NSW are from the trap and line fishery, which operates in nearshore and continental shelf waters (NSW Fisheries 2001). Although there are no signs of the large variation in recruitment to the fishery evident in some other snapper populations (e.g. South Australia, McGlennon et al. 2000), year-to-year variation in landings has often been high (Ferrell \& Sumpton 1997). In NSW, 2 and 3 yr old snapper dominate all landings, with fewer than $2 \%$ of fish landed being older than $10 \mathrm{yr}$ despite a potential longevity in excess of $30 \mathrm{yr}$ (NSW Fisheries 2001). Knowing the estuaries from which adult fish originate and their potential movement patterns as 2 to $4^{+}$yr olds is extremely valuable information for management of the fishery. The recruitment estuaries of adult snapper collected in the vicinity of Sydney were predominantly local, namely from Hawkesbury Estuary to Port Hacking. Few fish recruited from other estuaries, although there was some indication that some fish may have moved considerable distances, e.g. from Eden north to Sydney.

For other regions along the coast of NSW, 2 scenarios regarding replenishment of adult populations may be possible. A similar situation may exist to that in the Sydney region (i.e. snapper may move to adult populations from estuaries close by) suggesting that the populations are self-sustaining. Alternatively, estuaries in the vicinity of Sydney may replenish all coastal stocks of snapper, although such a scenario would imply that the Sydney estuaries produce $90 \%$ of the juveniles that subsequently move to the adult populations. It is unlikely that the Sydney estuaries produce more juveniles than other estuaries, because the time taken to collect similar numbers of juvenile snapper in all estuaries was approximately the same. Thus, for Sydney estuaries to replenish all coastal stocks of snapper, survival would have to be significantly greater in Sydney estuaries than in other estuaries. Although it seems likely that adult populations are replenished by snapper moving from estuaries close by, this would need to be confirmed by sampling and determining the origins of adult snapper collected north and south of the Sydney region.

By analysing several year classes of snapper over time, it will be possible to construct spatial models that identify the distance that snapper have moved from their recruitment estuary, and also the number of estuaries that contribute to a certain adult population. For example, evidence from $2^{+}$fish in the Sydney region suggests that adults in nearshore waters have come from the estuaries closest to them with little input from other estuaries. Whether $3^{+}$and $4^{+}$snapper show similar patterns is unknown, although older fish may be expected to move further from their recruitment estuaries, given that snapper are relatively mobile.

It is not known whether similar patterns would be found for $2^{+}$snapper sampled in different years, but given that these fish may have left the estuaries 6 to 12 mo previously they may have had relatively little time to move large distances. Differences in spatial models of replenishment between $2^{+}$snapper sampled in one year and $3^{+}$snapper sampled in the following year may also indicate predominant movement patterns of snapper once they have left estuaries. For example, if $2^{+}$snapper in the vicinity of Sydney had come from estuaries predominantly in the Sydney region and $3^{+}$snapper in the Sydney region had come from estuaries further a field then this may indicate movement away from Sydney. Such an interpretation assumes that there is no differential mortality in snapper from different places.

In conclusion, elemental fingerprints of fish allowed identification of the recruitment habitats of adult snapper, as well as connectivity between juvenile and adult populations. Although only one year class of adults was investigated, the results suggest that populations may be self-sustaining or relatively closed. Similar results have also been found for larvae from coral reefs (e.g. Jones et al. 1999, Swearer et al. 1999). Determining origins of several year classes of adults collected from a number of regions will allow the establishment of spatial models of population replenishment and provide estimates of connectivity among habitats. An understanding of connectivity between juvenile (e.g. 
estuary) and adult populations has considerable implications for fisheries management and the effective conservation of fishes, because it may determine the extent to which populations are self-sustaining.

Acknowledgements. I thank J. Hughes for assisting with collections of fish and preparation of samples, D. Ferrell for providing and ageing adult otoliths, J. Tsiros for help with analysing samples by ICP-MS, R. Millar for use of his mixed stock composition estimation program (HISEA), and both R. Millar and M. Haddon for discussions regarding maximum likelihood-based analyses. The study was conducted while the author held an ARC QEII research fellowship and was funded by an ARC large grant and the Fisheries Research Development Corporation (no. 98/139).

\section{LITERATURE CITED}

Anderson MJ (2001) A new method for non-parametric multivariate analysis of variance in ecology. Aust J Ecol 26: $32-46$

Bell JD, Worthington DG (1993) Links between estuaries and coastal rocky reefs in the lives of fishes from south-eastern Australia. In: Battershill CB, Schiel DR, Jones GP, Cresse RG, MacDiarmid AB (eds) Proc 2nd Int Temperate Reefs Symp, National Institute of Water and Atmospheric Research, Wellington, NZ, p 85-91

Bucher D, Saenger P (1991) An inventory of Australian estuaries and enclosed marine waters: an overview of results. Aust Geog Stud 29:370-381

Campana SE (1999) Chemistry and composition of fish otoliths: pathways, mechanisms and applications. Mar Ecol Prog Ser 188:263-297

Campana SE, Gagne JA (1995) Cod stock discrimination using ICPMS elemental assays of otoliths. In: Secor DH, Dean JM, Campana SE (eds) Recent developments in fish otolith research. University of South Carolina Press, Columbia, SC, p 671-691

Campana SE, Fowler AJ, Jones CM (1994) Otolith elemental fingerprinting for stock discrimination of Atlantic cod (Gadus morhua) using laser ablation ICPMS. Can J Fish Aquat Sci 51:1942-1950

Campana SE, Gagne JA, McLaren JW (1995) Elemental fingerprinting of fish otoliths using ID-ICPMS. Mar Ecol Prog Ser 122:115-120

Campana SE, Chouinard GA, Hanson JM, Frechet A, Brattey J (2000) Otolith elemental fingerprints as biological tracers of fish stocks. Fish Res 46:343-357

Coutant CC, Chen CH (1993) Strontium microstructure in scales of freshwater and estuarine striped bass (Morone saxatilis) detected by laser ablation mass spectrometry. Can J Fish Aquat Sci 50:1318-1323

DiBacco C, Levin LA (2000) Development and application of elemental fingerprinting to track the dispersal of marine invertebrate larvae. Limnol Oceanogr 45:871-880

Dove SG, Kingsford MJ (1998) Use of otoliths and eye lenses for measuring trace-metal incorporation in fishes: a biogeographic study. Mar Biol 130:377-387

Edmonds JS, Moran MJ, Caputi N (1989) Trace element analysis of fish sagittae as an aid to stock identification: pink snapper (Chrysophrys auratus) in Western Australian waters. Can J Fish Aquat Sci 46:50-54

Edmonds JS, Caputi N, Morita M (1991) Stock discrimination by trace-element analysis of otoliths of orange roughy
(Hoplostethus atlanticus), a deep-water marine teleost Aust J Mar Freshw Res 42:383-389

Edmonds JS, Lenanton RCJ, Caputi N, Morita M (1992) Trace elements in the otoliths of yellow-eye mullet (Aldrichetta forsteri) as an aid to stock identification. Fish Res 13:39-51

Ferrell DJ, Sumpton W (1997) Assessment of the fishery for snapper (Pagrus auratus) in Queensland and New South Wales. FRDC Report No 93/074, Queensland Department of Primary Industries \& New South Wales Fisheries Research Institution

Gillanders BM (2002) Temporal and spatial variability in elemental composition of otoliths: implications for determining stock identity and connectivity of populations. Can J Fish Aquat Sci 59:669-679

Gillanders BM, Kingsford MJ (1996) Elements in otoliths may elucidate the contribution of estuarine recruitment to sustaining coastal reef populations of a temperate reef fish. Mar Ecol Prog Ser 141:13-20

Gillanders BM, Kingsford MJ (2000) Elemental fingerprints of otoliths of fish may distinguish estuarine 'nursery' habitats. Mar Ecol Prog Ser 201:273-286

Gillanders BM, Sanchez-Jerez P, Bayle-Sempere JT, RamosEspla A (2001) Trace elements in otoliths of the twobanded bream from a coastal region in the south-west Mediterranean: are there differences among locations? J Fish Biol 59:350-363

Jones GP, Milicich MJ, Emslie MJ, Lunow C (1999) Selfrecruitment in a coral reef fish population. Nature 402: 802-804

Kalish JM (1990) Use of otolith microchemistry to distinguish the progeny of sympatric anadromous and non-anadromous salmonids. Fish Bull 88:657-666

Kalish JM, Livingston ME, Schofield KA (1996) Trace elements in the otoliths of New Zealand blue grenadier (Macruronus novaezelandiae) as an aid to stock discrimination. Mar Freshw Res 47:537-542

Kennedy BP, Blum JD, Folt CL, Nislow KH (2000) Using natural strontium isotopic signatures as fish markers: methodology and application. Can J Fish Aquat Sci 57:2280-2292

Ludden JN, Feng R, Gauthier G, Stix J, Shi L, Francis D, Machado N, Wu G (1995) Applications of LAM-ICP-MS analysis to minerals. Can Mineral 33:419-434

Manly BFJ (1997) Randomization, bootstrap and Monte Carlo methods in biology. Chapman \& Hall, London

McGlennon D, Jones GK, Baker J, Jackson WB, Kinloch MA (2000) Ageing, catch-at-age and relative year-class strength for snapper (Pagrus auratus) in northern Spencer Gulf, South Australia. Mar Freshw Res 51:669-677

Millar RB (1987) Maximum likelihood estimation of mixed stock fishery composition. Can J Fish Aquat Sci 44: $583-590$

Millar RB (1990a) Comparison of methods for estimating mixed stock fishery composition. Can J Fish Aquat Sci 47: $2235-2241$

Millar RB (1990b) A versatile computer program for mixed stock fishery composition estimation. Can Tech Rep Fish Aquat Sci 1753

Milton DA, Chenery SR, Farmer MJ, Blaber SJM (1997) Identifying the spawning estuaries of the tropical shad, terubok Tenualosa toli, using otolith microchemistry. Mar Ecol Prog Ser 153:283-291

NSW Fisheries (2001) Status of fisheries resources 1999/2000. NSW Fisheries, Cronulla

Patterson HM, Thorrold SR, Shenker JM (1999) Analysis of otolith chemistry in Nassau grouper (Epinephelus striatus) from the Bahamas and Belize using solution-based ICPMS. Coral Reefs 18:171-178 
Patterson WP, Smith GR, Lohmann KC (1993) Continental paleothermometry and seasonality using the isotopic composition of aragonitic otoliths of freshwater fishes. Geophys Monogr 78:191-202

Proctor CH, Thresher RE, Gunn JS, Mills DJ, Harrowfield IR, Sie SH (1995) Stock structure of the southern bluefin tuna Thunnus maccoyii: an investigation based on probe microanalysis of otolith composition. Mar Biol 122:511-526

Rooker JR, Secor DH, Zdanowicz VS, Itoh T (2001) Discrimination of northern bluefin tuna from nursery areas in the Pacific ocean using otolith chemistry. Mar Ecol Prog Ser 218:275-282

Secor DH (1992) Application of otolith microchemistry analysis to investigate anadromy in Chesapeake Bay striped bass Morone saxatilis. Fish Bull 90:798-806

Swearer SE, Caselle JE, Lea DW, Warner RR (1999) Larval

Editorial responsibility: Otto Kinne (Editor),

Oldendorf/Luhe, Germany retention and recruitment in an island population of a coral-reef fish. Nature 402:799-802

Thorrold SR, Jones CM, Campana SE (1997) Response of otolith microchemistry to environmental variations experienced by larval and juvenile Atlantic croaker (Micropogonias undulatus). Limnol Oceanogr 42:102-111

Thorrold SR, Jones CM, Swart PK, Targett TE (1998) Accurate classification of juvenile weakfish Cynoscion regalis to estuarine nursery areas based on chemical signatures in otoliths. Mar Ecol Prog Ser 173:253-265

Thorrold SR, Latkoczy C, Swart PK, Jones CM (2001) Natal homing in a marine fish metapopulation. Science 291: 297-299

West RJ, Thorogood C, Walford T, Williams RJ (1985) An estuarine inventory for New South Wales, Australia. Department of Agriculture New South Wales, Sydney

Submitted: November 26, 2001; Accepted: May 7, 2002

Proofs received from author(s): August 16, 2002 